\title{
El Modelo Chileno desde una ética de justicia y de igualdad de las oportunidades humanas
}

\author{
Andrés Araya Rosales \\ Universidad Católica del Norte, Coquimbo Chile. \\ Email: aaraya@ucn.cl
}

\section{Mauricio Gallardo Altamirano \\ Universidad Católica del Norte, Coquimbo Chile. Email: megallardo@ucn.cl}

\begin{abstract}
Resumen: Tras más de dos décadas de democracia, en Chile, perdura el modelo económico desarrollado durante el régimen militar de Augusto Pinochet. Este modelo ha mostrado logros en materia económica, destacando sobre todo su ordenamiento macroeconómico, apoyado en una disciplina fiscal y una política monetaria que ha mantenido una inflación baja y estable. Se han logrado avances en el crecimiento económico, en disminución de la pobreza y en el mejoramiento del nivel de vida de los ciudadanos. Estos avances han dado lugar también a una clase media emergente más amplia, que recientemente ha salido a la escena política a reclamar nuevos derechos, expresando descontento frente al modelo a través de un fuerte movimiento social. En este artículo sostenemos, que a pesar de los logros económicos alcanzados, el modelo económico chileno ha estado ajeno a los principios de justicia y de igualdad de oportunidades que deberían regir en una democracia liberal.
\end{abstract}

Palabras clave: Modelo económico, liberalismo, justicia, igualdad.

\section{The Chilean Model seen from an ethics of justice and of equal human opportunities}

\begin{abstract}
After two decades of democracy in Chile, the economic model developed during the Augusto Pinochet military regime remains. This model has shown remarkable economic achievements, mainly on its macroeconomic management, supported by a strict fiscal discipline and a successful monetary policy which has kept inflation low and stable. Remarkable achievements have been accomplished as well in economic growth, poverty reduction and improvement in the citizens standard of living. These advances have also led to a broader emerging middle class who has recently come to the political scene claiming new rights and expressing dissatisfaction toward the model through a strong social movement. In this paper we argue, that despite the great economic achievements, the Chilean economic model has been alien to the principles of justice and equality of human opportunities that should prevail in a liberal democracy.
\end{abstract}

Keywords: Economic model, Liberalism, Justice, equality 


\title{
O modelo chileno a partir de uma ética de justiça e de igualdade das oportunidades humanas
}

\begin{abstract}
Resumo: Depois de mais de duas décadas de democracia, no Chile perdura modelo econômico desenvolvido durante o regime militar de Augusto Pinochet. Este modelo mostrou conquistas econômicas, salientando especialmente a sua organização macroeconômica, apoiada por uma disciplina fiscal e uma política monetária que manteve a inflação baixa e estável. Registaram-se progressos no crescimento econômico, redução da pobreza e melhoramento dos padrões de vida dos cidadãos. Estes avanços têm dado lugar também, a uma ampla classe média emergente, que passou recentemente a reivindicar novos direitos no cenário político, expressando insatisfação com o modelo através de um movimento social forte. Argumenta-se neste artigo que, apesar dos ganhos econômicos alcançados, o modelo econômico chileno tem sido alheio aos princípios de justiça e igualdade de oportunidades que deveriam reger numa democracia liberal.
\end{abstract}

Palavras-chave: modelo econômico, liberalismo, justiça, igualdade.

$* * *$

\section{Introducción}

El modelo económico que se instauró en Chile durante el régimen militar de Augusto Pinochet, ha sido conservado de manera casi intacta durante el período democrático que se inició en 1990. Tras más de dos décadas de democracia y casi treinta años de haberse iniciado, este modelo aparece como el más exitoso de América Latina, debido a sus notables logros en materia económica. Sin embargo, desde el año 2011 ha sido objeto de fuertes cuestionamientos por los movimientos sociales y más recientemente en los círculos intelectuales (por ejemplo: Atria et al., 2013; Rivera y Martner, 2013). En el ambiente político chileno y en la pasada campaña electoral del año 2013, se ha manifestado también un discurso político que refleja una inconformidad aparentemente paradójica de la ciudadanía, ante un modelo que ha superado las expectativas en materia de crecimiento económico, en comparación con otros países de la región de América Latina.

El problema que se aborda en este ensayo es el de brindar un análisis del modelo chileno en cuanto a sus logros y limitaciones, para tratar de explicar las causas de tal inconformidad social. El ensayo se sustenta en un enfoque conceptual orientado hacia principios ideales de una democracia liberal plena (Rawls, 1993), construida a partir de una concepción política de la justicia y de la igualdad de oportunidades humanas. Esta visión se contrapone con el enfoque conceptual del fundamentalismo de mercado o neoliberalismo, en cuyo seno ideológico se generó el modelo económico analizado.

Reconociendo los logros del modelo en materia económica, en el ensayo se critica el déficit de justicia y de igualdad de oportunidades que lo caracteriza. Se espera contribuir al debate y a la reflexión sobre los desafíos de la democracia chilena y de su modelo económico. 
El ensayo se encuentra estructurado del siguiente modo. En la sección siguiente se presenta el marco analítico conceptual. Luego sigue una sección que describe el modelo chileno y relata algunas de las recientes críticas de que ha sido objeto. En la sección posterior se analiza el déficit de justicia y de desigualdad de oportunidades del modelo y finalmente se ofrecen las conclusiones y algunas propuestas de política económica.

\section{Conceptualización de una ética de la justicia y de la igualdad de oportunidades}

\section{Dos liberalismos}

El liberalismo es una corriente de pensamiento que ha hecho aportes fundamentales no solamente para el respeto de las libertades individuales, sino también para el desarrollo de una concepción política de la justicia social y de la democracia. Sin embargo, con frecuencia, esta corriente de pensamiento aparece en el ámbito académico como el Satán y el peor enemigo intelectual de la equidad económica y social. La razón de ello, es que en el seno del pensamiento liberal se han desarrollado no una, sino varias corrientes intelectuales, dentro de las cuales la que más ha destacado por su influencia en el sistema económico, es aquella que tiene su origen en los desarrollos de Ludwig von Mises, Friedrich von Hayek y Milton Friedman. Se trata del así llamado fundamentalismo de mercado, también conocido como neoliberalismo. Sin embargo, dentro del mismo liberalismo hay otra corriente de pensamiento muy distinta, que acá atribuimos al filósofo John Rawls y al economista John Roemer. Este otro liberalismo, se funda en una concepción política de la justicia basada en un acuerdo de cooperación entre iguales y defiende el principio de igualdad de oportunidades humanas.

Ambas concepciones liberales sitúan al individuo en el centro de la esfera política y comparten los principios de la libertad individual, la democracia representativa, el respeto a la propiedad privada y el libre mercado. En contraposición a las concepciones políticas que dominaron en el socialismo real y en otros tipos de totalitarismos, para el liberalismo, la libertad individual no tiene porque someterse a un "interés general" determinado por un partido o por una cúpula de poder. Por el contrario, la esfera de lo político, debe estar fundada en el respeto pleno a las libertades de los individuos que conforman la sociedad.

Sin embargo, en el liberalismo fundamentalista de mercado, la sociedad y lo político, aparecen solamente como una suma o confluencia de voluntades individuales, carentes de cualquier sentido de justicia social o distributiva. Para Hayek (1944), lo que algunos llaman "fines sociales" son simplemente fines en los cuales muchos individuos coinciden, para la satisfacción de sus propios deseos personales. 
El mismo Hayek (1976, 1978), considera que la justicia social es un concepto vacío, puesto que en una economía de mercado, los individuos participan en un libre juego en el que se intercambian entre sí, bienes y servicios, sin que tenga que producirse una distribución de riqueza que pueda ser catalogada de alguna manera como justa o injusta. Los individuos libres que participan en el juego, pueden ganar o perder, en dependencia de cómo aprovechen sus habilidades, sus circunstancias particulares e incluso su suerte. Entonces, según él, no tiene por qué invocarse el poder del Estado para revertir los resultados desfavorables que puedan obtenerse en tal juego.

Por otro lado, ante la objeción de que las condiciones iniciales para participar en el juego sean distintas para los distintos individuos, Hayek (1976) responde que por un lado, precisamente uno de los objetivos del juego de mercado, es hacer el mejor uso posible de las inevitables diferencias en habilidades, conocimientos y condiciones del ambiente, que poseen los distintos individuos. Mientras tanto, los diversos dones morales, intelectuales y materiales que los padres puedan heredar a sus hijos, son parte de los activos que está permitido transferir en dicho juego. Los logros alcanzados en el juego, precisamente son creados, no solo para disfrutarlos por sí mismos, sino también para transferirlos a los hijos.

En otra de sus obras (Hayek, 1988), el mismo autor argumenta que la sociedad no es un sistema "racionalmente organizado" que pueda ser susceptible de ser mejorado por alguna mente o grupo de mentes humanas, en forma consciente o deliberada, sino que es el resultado de un proceso espontáneo de millones de individuos que siguen sus propios intereses.

Tal visión de lo social, centrada en la lógica del mercado, contrasta con el liberalismo de Rawls y de Roemer. En la concepción de Rawls (1971, 1993, 2001), la sociedad política no es solamente una confluencia espontánea de voluntades individuales en donde la justicia la determina el libre juego del mercado. La sociedad política es entendida por este autor, como un sistema de cooperación entre individuos libres e iguales, capaces de alcanzar acuerdos racionales y razonables. Tal cooperación es imperfecta y compleja, puesto que en ella confluyen una pluralidad de intereses y una diversidad de teorías comprensivas. Sin embargo, tal idea de la cooperación social se encuentra fuertemente arraigada en los ideales de nuestra cultura política y democrática, e incluso está presente de alguna manera en las constituciones republicanas y en las leyes que nos rigen.

La sociedad, de acuerdo con este filósofo (Rawls, 1971, 2001), es un sistema equitativo de cooperación, ligado a dos conceptos fundamentales que prevalecen en los valores de nuestra cultura occidental contemporánea: la idea de los ciudadanos como personas libres e iguales y la idea de una sociedad bien ordenada, fundada sobre una estructura básica de instituciones capaces de satisfacer unos principios comunes de justicia política, reconocidos por los participantes de tal cooperación. La cooperación social según él no es igual a la actividad social coordinada. Esta última 
puede ser impuesta, por ejemplo, a través de una dictadura o de un gobierno totalitario. $\mathrm{O}$ a nuestro juicio, puede ser también el resultado espontáneo de la confluencia de intereses individuales bajos ciertas reglas reconocidas de intercambio comercial, tal como lo es por ejemplo, el sistema social operante bajo las reglas del mercado en la concepción de Hayek. La cooperación social debe estar guiada por reglas públicamente reconocidas y aceptadas voluntariamente por los ciudadanos cooperantes. Pero además, debe ser equitativa y reconocida como un sistema de cooperación entre iguales. Debe implicar por lo tanto reciprocidad y mutualidad de derechos y deberes. Debe además incorporar una ventaja racional, en el sentido que los cooperantes conscientemente acceden a tal cooperación, porque de ella se benefician mutuamente.

Cabe hacer notar, que el liberalismo de este filósofo no se refiere a la sociedad como un sistema de cooperación en el sentido marxista. Se trata claramente de una concepción liberal, según la cual, la base de tal cooperación social no es un ideal colectivo o de sociedad comunitaria, sino el acuerdo libre entre ciudadanos iguales, que operan en un sistema de mercado y que desean conscientemente y por voluntad propia, obtener beneficios individuales de tal cooperación. Pero estos ciudadanos libres e iguales, también se encuentran guiados por ciertos valores y principios compartidos de equidad y de justicia, los cuales brindan contenido al pacto social que establecen.

Así, al referirnos a lo político, no podemos eludir según Rawls (2001), la cuestión fundamental a saber: definir cuáles son los principios de justicia que mejor reflejan los términos equitativos de la cooperación social. Esto es (Rawls, 2001: 30): “¿Cuál es la concepción política de la justicia que mejor define los términos de la cooperación entre ciudadanos considerados como libres e iguales, razonables y racionales, y como miembros normales y plenamente cooperativos de la sociedad, a lo largo de toda una vida y de una generación a la siguiente?". La formulación de tal interrogante indica, que al contrario de Hayek, para este otro liberalismo la sociedad si es susceptible de ser mejorada racionalmente por los ciudadanos que la conforman, a partir de una concepción política compartida de la justicia. Frente al reduccionismo del fundamentalismo de mercado, Rawls se remite a valores y principios compartidos en nuestra civilización, por ciudadanos libres e iguales, que poseen la capacidad de llegar a acuerdos vinculantes, para construir una estructura básica de instituciones que garanticen equidad y justicia.

Uno de los pilares de la concepción liberal de Rawls, es el principio de igualdad de oportunidades. Una concepción política de la justicia, que implique relación equitativa entre ciudadanos libres e iguales, requiere que estos se encuentren en igualdad de condiciones para desarrollar sus talentos y para gozar de los beneficios de su propio esfuerzo. Este principio, está desarrollado luego en Roemer (1998). Para este último, a diferencia de Hayek, los “activos de cuna” no son coherentes con una lógica liberal de libre competencia. Tales activos proporcionan ventajas y desventajas decisi- 
vas, que invalidan el esfuerzo de unos y sobre premian el de otros. Para un liberalismo consecuente como el de Roemer (1998), la libre competencia debe ser justa, en el sentido de que esta debe partir de una igualación previa del campo de juego. Por ello, la sociedad debe garantizar a todos los seres humanos, desde el momento de su gestación en el vientre materno y durante la infancia y la adolescencia, la oportunidad de desarrollar sus potencialidades de manera que sus resultados en la edad adulta no dependan de sus circunstancias particulares de cuna, sino solamente de su esfuerzo personal.

\section{Una concepción política de la justicia}

En la concepción de Rawls (2001: 31) una sociedad bien ordenada comprende tres elementos constitutivos. En primer lugar, requiere una concepción compartida de la justicia política, en donde cada cual acepta y sabe que todos los demás aceptan, los mismos principios de justicia política. En tal sentido, una sociedad bien ordenada no es solamente una suma de voluntades en un sistema de libre mercado, sino que requiere un sistema de valores y principios de justicia comúnmente aceptados de manera libre por los ciudadanos.

En segundo lugar, una sociedad bien ordenada requiere la existencia de una estructura básica, que satisfaga los principios de justicia política. Tal estructura básica está conformada por las instituciones sociales y el modo en que estas se acoplan para formar un sistema de cooperación que satisfaga los principios de la justicia política. Tal estructura básica, es la piedra angular que conforma el sistema de garantías que protegen los derechos de los individuos, como personas que coexisten en condiciones de equidad y de igualdad de oportunidades. Constituye el objeto principal de la justicia política, porque tal estructura afecta las aspiraciones, las oportunidades y el desarrollo de las capacidades de los ciudadanos.

En tercer lugar, una sociedad bien ordenada requiere que los ciudadanos tengan un sentido efectivo de la justicia, en tanto sean capaces de reconocer y de aplicar tales principios públicamente reconocidos y de actuar mayormente conforme el deber que atañe a los mismos. Nótese que esta tercera condición requiere que los ciudadanos sean personas con cierto nivel de educación y con capacidad de discernimiento moral. Una sociedad bien ordenada no es posible de alcanzar en países donde las personas carecen de la educación necesaria para reconocer los principios de la justicia política y para participar en la vida pública de acuerdo con tales principios. Tampoco es posible en países en donde se han perdido los valores que guían la conducta humana civilizada y la capacidad de discernimiento moral.

La tercera condición está ligada a la idea de que las personas que participan en la cooperación social son seres libres e iguales. Solamente al ser libres e iguales, los ciudadanos serán plenamente capaces de participar en la cooperación social. Ello requiere que sean poseedores de dos faculta- 
des necesarias para establecer tal cooperación: un sentido de la justicia y una concepción del bien. Lo primero es la capacidad de entender, aplicar y obrar según los principios de la justicia política que definen los términos equitativos de la cooperación social. Lo segundo, es la capacidad de poseer, revisar y perseguir una concepción moral acerca de lo que tiene valor en la vida humana. O dicho de otro modo: de lo que se considera una vida plenamente valiosa.

La base de la igualdad es poseer tales cualidades morales que hagan posible participar en la cooperación social. Los ciudadanos son libres según Rawls (2001) en los sentidos que a continuación se indican. Por un lado, se conciben a sí mismos, y unos a otros, con la facultad moral de poseer una concepción del bien. Por el otro, se ven a sí mismos con derecho a presentar exigencias a sus instituciones para promover sus concepciones del bien. Lo segundo nos indica que la inconformidad social tiene un sentido positivo. Ya que esta puede ser la manera en que se manifiestan las nuevas exigencias para mejorar las instituciones de la sociedad.

La idea de una sociedad bien ordenada es en sí una idealización. No existe, ni ha existido tal estado de sociedad bien ordenada en la historia real. Sin embargo, tal idealización tiene un valioso sentido orientador y heurístico, que ayuda a definir con claridad la idea de la cooperación social equitativa y que proporciona un criterio para comparar distintas concepciones de la justicia política. Tal idea, proporciona además, una guía para encontrar la dirección adecuada de las reformas sociales y políticas que deben implementarse en una sociedad para alcanzar mayores niveles de justicia.

El ejercicio intelectual de analizar cómo sería idealmente una sociedad bien ordenada, permite explorar los límites de lo políticamente practicable. Es decir, nos permite aproximar una idea sobre lo que sería un sistema político de perfección democrática, formado por individuos que han convenido un acuerdo de cooperación equitativo.

Los términos de la equidad de tal cooperación, según Rawls (2001), han de venir dados por el mismo acuerdo entre los participantes. Sin embargo, para que sea un acuerdo de justicia política no debe permitirse a ninguno, negociar bajo condiciones ventajosas. Sería injusto por ejemplo, hacer un acuerdo social entre los individuos partiendo de un statu quo, en el cual unos se encuentran mejor situados que otros. Para que sea un acuerdo equitativo entre personas libres e iguales, los participantes del acuerdo deberían estar situados simétricamente, al margen de las circunstancias particulares de sus orígenes de clase social, raza, dotación de educación y otras circunstancias.

Para poder describir cómo sería un acuerdo entre ciudadanos simétricamente situados, Rawls $(1971,2001)$ recurre al artilugio de una posición neutral hipotética que él llama "la posición original". En tal posición los participantes se encuentran bajo "el velo de la ignorancia”, en el sentido de que están despojados de todos sus privilegios y además desconocen el 
lugar que les va a tocar en la sociedad que esperan construir. La posición original obviamente es hipotética, no histórica. No ha ocurrido, ni tiene que ocurrir. Al ser un acuerdo hipotético, aparentemente es irrelevante. Sin embargo, este mecanismo de representación permite modelar tanto las condiciones equitativas para un acuerdo entre iguales, como las restricciones aceptables sobre las razones para que las partes puedan acordar los principios de justicia.

En la posición original, un acuerdo entre ciudadanos libres e iguales debería conducir según Rawls (2001) a la promulgación de los siguientes principios básicos: ${ }^{1}$

- Principio de igual libertad: "cada persona tiene un derecho irrevocable a un esquema plenamente adecuado de libertades básicas iguales, que sea compatible con un esquema similar de libertades para todos” (Rawls, 2001: 73).

- Principio de igualdad de oportunidades: "las desigualdades sociales y económicas tienen que estar vinculadas a cargos y posiciones abiertas para todos en igualdad equitativa de oportunidades” (Rawls, 2001: 73).

- Principio de diferencia: 2 "las desigualdades deben de redundar en un mayor beneficio para los miembros menos favorecidos de la sociedad” (Rawls, 2001: 73).

La concepción política de la justicia no constituye según Rawls (2001), una teoría comprensiva que pretenda erigirse por sobre las demás teorías comprensivas existentes en la sociedad. En realidad no existe tal doctrina comprehensiva en la que los ciudadanos puedan ponerse de acuerdo respecto de las cuestiones fundamentales de la justicia política. En una sociedad bien ordenada lo que debe existir es un pluralismo razonable y un consenso entrecruzado compartido por diversas doctrinas que coexisten.

Un consenso entrecruzado es posible si: sus exigencias se limitan a la estructura básica, si su aceptación no presupone ninguna visión comprehensiva particular y si se comparten ciertas ideas de una cultura política referenciada en principios aceptados de justicia.

En términos básicos, esta concepción política de la justicia es una concepción de valores compartidos, la cual se construye para un objeto específico: el desarrollo de la estructura básica de una sociedad democrática, formada por ciudadanos libres e iguales, no en el discurso, sino en sus condiciones reales de vida. Aceptar dicha concepción no presupone aceptar ninguna doctrina comprehensiva particular. Se trata solamente de una concepción cuyos principios expresan una familia de valores políticos reconocidos, que se deben aplicar a la estructura básica. En lo posible, tal concepción política de la justicia, se formula sólo con ideas fundamentales implícitas en la cultura política de una sociedad democrática. 
La justificación pública de la concepción política de la justicia, según Rawls (2001), se fundamenta en la existencia de valores compartidos por los ciudadanos y en la posibilidad de alcanzar un consenso razonable entre ciudadanos libres e iguales. La justificación pública no es un acuerdo completo, sino solamente la limitación del desacuerdo en las controversias esenciales a través de un "equilibrio reflexivo", que obedece a "juicios razonados". Estos últimos, son aquellos juicios "que se emiten en condiciones favorables al ejercicio de nuestras facultades de razón y de nuestro sentido de la justicia” (Rawls, 2001: 55), es decir, en condiciones que se acercan a la imparcialidad. Nuestros juicios razonados pueden entrar en conflicto obviamente con los de las otras personas y con los que nosotros mismos nos formulamos bajo distintas circunstancias. Hay un equilibrio reflexivo estricto, cuando la persona adopta una concepción de la justicia política que resulta aceptable y consistente, con el menor número de revisiones en sus juicios iniciales. Hay un equilibrio reflexivo amplio, cuando se adopta una concepción de la justicia política que ha considerado cuidadosamente las concepciones alternativas y la fortaleza de sus argumentos. De acuerdo con Rawls (2001: 57) en una sociedad bien ordenada los ciudadanos son capaces de alcanzar un equilibrio reflexivo amplio.

\section{Igualdad de oportunidades}

El principio de igualdad de oportunidades se encuentra fuertemente arraigado hoy en día en los valores de la democracia occidental, aunque sigue habiendo una brecha importante entre tal ideal y la práctica política y social.

En la democracia occidental, según Roemer (1998), existen dos sentidos en los que se utiliza el término de "igualdad de oportunidades". El primero de ellos es el "principio de no discriminación”. De acuerdo con este principio, al momento de acceder a un cargo o posición, todas las personas que tengan los atributos necesarios para ejercerlo, deben tener derecho a competir para acceder a dicho cargo o posición. Pero además, la selección de las personas para ocupar tal cargo o posición, debe regirse solamente por los atributos relevantes requeridos para el ejercicio del cargo y no por otras razones ajenas a tales requerimientos.

El segundo sentido en que se usa el concepto de igualdad de oportunidades corresponde al "principio de igualación del campo de juego". Según este principio, todas aquellas personas que de manera innata tienen el potencial para ejercer un cargo o posición en la sociedad, deben haber tenido la oportunidad de desarrollar el potencial para poder ejercerlo.

Es este segundo sentido el que sostiene Rawls (1971, 2001), al indicar que la igualdad de oportunidades no solamente exige que los cargos y las posiciones sociales estén abiertas a todos los ciudadanos en un sentido formal, sino además, que todos tengan efectivamente la oportunidad equitativa de llegar a ocuparlos, independientemente de sus circunstancias sociales o de otras condiciones que están fuera de su control. De acuerdo con 
ello, no debería existir ningún tipo de privilegios o ventajas atribuibles a tales circunstancias exógenas, al momento de acceder a algún cargo o posición. La consecuencia lógica es que todas las personas deberían tener derecho a adquirir la misma calidad de salud y alimentación, así como la misma dotación de capital humano (educación de igual calidad), durante el proceso de formación de sus capacidades. Es decir, desde la gestación en el vientre materno, hasta la edad en que se alcanza la adultez.

Generar igualdad de oportunidades significa entonces, garantizar a las personas un proceso de formación física e intelectual, que les permita desarrollar sus talentos y habilidades para poder competir en igualdad de condiciones en el juego del mercado. Se trata entonces, no solo de disfrutar de la libertad de participar en tal juego en el sentido de Hayek (1976), sino también de participar en él en igualdad de condiciones. Para ello, el campo de juego debe estar igualado, de manera que todos tengan las mismas chances de aprovechar sus talentos innatos. ${ }^{3}$

En una sociedad de igualdad de oportunidades la educación básica y media deben ser provistas con igual calidad para todos los ciudadanos de manera universal. Pero además, deben garantizarse universalmente, la alimentación adecuada y las condiciones de salud de las niñas y niños, y de las mujeres embarazadas. Solo de esa manera se puede garantizar que las personas adquieran una formación que les permita competir después en el mercado, en condiciones de igualdad.

\section{El modelo chileno}

\section{Orígenes del modelo}

El modelo económico chileno fue implementado en época de dictadura, durante el régimen militar de Augusto Pinochet. Sus artífices intelectuales fueron un grupo de economistas chilenos formados en la Universidad de Chicago, cuyo principal referente era el profesor Milton Friedman. Los miembros del grupo fueron conocidos como los “Chicago Boys”. Las bases del modelo se plasmaron en un libro denominado "El Ladrillo” (De Castro, 1973) en el que colaboran varios miembros de tal grupo.

El modelo surge en el contexto de la Guerra Fría, en donde el pensamiento liberal de occidente se confrontaba al comunismo soviético. Por ello, en el contexto ideológico, el modelo surge como una reacción al socialismo cubano, inspirado en el afán de mostrar las bondades del capitalismo en un país de América Latina que había vivido además la experiencia socialista del gobierno de Salvador Allende.

En “El Ladrillo”, al hacer el diagnóstico de la situación económica chilena, se señala que los principales problemas de las décadas anteriores eran: una baja tasa de crecimiento del PIB, un estatismo exagerado, la escasez de empleos productivos, la inflación, el atraso agrícola, y la existencia 
de condiciones de extrema pobreza en importantes sectores de la población. Estos problemas estarían generando a su vez algunos efectos negativos como los siguientes: mala asignación de los recursos productivos, limitado desarrollo del sector externo, baja tasa de crecimiento del PIB per cápita, acción indebida de grupos poderosos, déficit fiscales, cambio frecuente de políticas económicas, mal uso del poder político y déficit de abastecimiento alimenticio.

Luders (2012), señala que las políticas económicas establecidas, son semejantes a las propuestas por la Misión Klein Saks, contratada en la década de 1950 por el gobierno del presidente Carlos Ibañez del Campo y que fueron descontinuadas por la presión política de los años siguientes. En esencia, tal Misión pretendía entre otras cosas: liberalizar substancialmente el comercio exterior, los precios y los mercados de factores de producción, subir la tasa de interés real activa a niveles positivos y compatibles con los niveles de rentabilidad de los activos, privatizar las empresas estatales, reformar substancialmente el sistema de seguridad social, equilibrar las finanzas públicas, racionalizar el gasto público, e imponer disciplina monetaria.

El contexto en que se implanta el modelo estuvo marcado por la respuesta económica a una situación de fuerte desabastecimiento de alimentos que caracterizó al último año del gobierno de Salvador Allende, En donde se experimentaron también fijaciones de precios y un mercado negro muy desarrollado. Era además un contexto de fuertes divisiones políticas en la población, incluso al interior de las familias. Al eliminar las fijaciones de precios, rápidamente desapareció el mercado negro, pero el ajuste se produjo a precios mayores, lo que provocó una alta inflación en los primeros años de implantado el nuevo modelo. De hecho, la inflación en el período 1974-1977 fue del orden del 700\% anual.

Sebastián Edwards (Larraín y Vergara, 2001: 28) señala que las principales reformas introducidas por la dictadura de Augusto Pinochet fueron las siguientes:

- "Una reforma tributaria radical, dirigida a eliminar un desequilibrio fiscal endémico, suprimir las distorsiones más importantes y evitar las crisis recurrentes de la balanza de pagos.

- La apertura (unilateral) al comercio internacional, a través de la eliminación de las restricciones cuantitativas y la aplicación de un arancel uniforme del $10 \%$ a las importaciones.

- Un programa importante de privatizaciones que abarcó la mayoría (aunque no la totalidad) de las áreas de la economía.

- Una profunda reforma financiera que desreguló el mercado interno de capitales y permitió un acceso bastante irrestricto al sector bancario. 
- Una reforma laboral dirigida a aumentar la flexibilidad del mercado de trabajo, y reducir el grado y la intensidad de los conflictos laborales.

- La privatización del sistema de seguridad social”.

\section{Resultados económicos del modelo}

El modelo económico chileno ha sido exitoso en sus logros macroeconómicos. El orden fiscal y la independencia de la política monetaria del Banco Central generaron un marco de estabilidad que se tradujo en condiciones adecuadas para el desarrollo de los negocios. La apertura comercial permitió aprovechar las ventajas comparativas del país y trajo ganancias importantes en productividad (véase Coymans, 1999). En el país se generó confianza para la inversión y las políticas macroeconómicas estuvieron acompañadas de un paquete de políticas sociales.

En la tabla 1 se presentan algunos indicadores que muestran el éxito alcanzado por el modelo económico chileno. En la primera columna se indican las cifras del período que antecede al modelo y que corresponde a los convulsionados años de década de los sesenta. La siguiente columna corresponde al período de dictadura con el modelo ya consolidado. Le siguen las cifras de las dos primeras décadas de democracia.

\section{Tabla 1: Principales indicadores macroeconómicos y sociales de Chile, promedio de décadas.}

\begin{tabular}{|c|c|c|c|c|}
\hline Concepto & $1961-1970$ & $1980-1989$ & $1990-2000$ & $2001-2010$ \\
\hline Inflación anual (\%) & 27.8 & 20.7 & 8.5 & 3.2 \\
\hline PIB per cápita (en US\$ corrientes) & 747 & 1932 & 4411 & 8102 \\
\hline Crecimiento del PIB (\% anual, US $\$$ a precios constantes de 2005 ) & 4.1 & 4.4 & 6.5 & 3.9 \\
\hline Crecimiento del PIB per cápita ( $\%$ anual, a precios constantes de 2005 ) & 1.8 & 2.7 & 4.8 & 2.8 \\
\hline Total de reservas como $\%$ del PIB (incluye oro, US\$ corrientes) & 2.6 & 14.5 & 21.2 & 14.2 \\
\hline Comercio exterior como \% del PIB & 27.5 & 52.2 & 56.8 & 69.2 \\
\hline Ahorro interno bruto $(\%$ del PIB) & 17.9 & 19.0 & 25.4 & 28.1 \\
\hline Formación bruta de capital ( $\%$ del PIB) & 18.1 & 18.5 & 25.0 & 22.2 \\
\hline Tasa de mortalidad, menores de 5 años (por cada 1.000 ) & 111.6 & 24.7 & 13.6 & 9.4 \\
\hline Camas hospitalarias (por cada 1.000 personas) & 3.8 & 3.3 & 2.9 & 2.3 \\
\hline Médícos (por cada 1.000 pers onas) & 0.5 & 0.8 & 1.1 & 1.1 \\
\hline Tas a de natalidad, nacidos vivos en un año (por cada 1.000 personas) & 34.0 & 23.3 & 19.6 & 15.1 \\
\hline Esperanza de vida al nacer & 59.7 & 71.5 & 75.3 & 78.2 \\
\hline Tas a de fertilidad, total (nacimientos por cada mujer) & 4.9 & 27 & 23 & 1.9 \\
\hline Población urbana ( $\%$ del total) & 72.0 & 82.3 & 84.6 & 87.7 \\
\hline
\end{tabular}

Fuente: Banco Mundial.

Como puede observarse en las cifras de la tabla, el modelo económico redujo sustancialmente la inflación y en la última década logró mantenerla en torno a la meta del Banco Central (3\% anual). El PIB per cápita se ha incrementado casi 10 veces en 5 décadas, siendo particularmente fuerte el 
incremento obtenido en la primera década de democracia. Las reservas del Banco Central como porcentaje del PIB se incrementaron considerablemente. La economía pasó de un nivel de apertura menor que un tercio del PIB a uno cercano al 70\%. Crecieron en forma importante: la tasa de ahorro interno y la formación bruta de capital como porcentaje del PIB.

En cuanto a indicadores sociales, en décadas recientes Chile ha experimentado notables logros en: la esperanza de vida al nacer, la tasa de natalidad y la disminución de la mortalidad infantil. El número de médicos por habitante se incrementó. Se ha experimentado también un aumento en el porcentaje de población urbana y una disminución en la tasa de fertilidad. Se observa no obstante un deterioro en el número de camas hospitalarias (por cada 1000 personas).

Los logros en crecimiento económico y las políticas sociales repercutieron también en una disminución de la tasa de incidencia de la pobreza, tal como se muestra en el gráfico 1. Sin embargo, los avances en distribución del ingreso han sido bastante modestos, de acuerdo con el índice Gini mostrado en el mismo gráfico. De hecho, Chile es el país de la OECD con mayor desigualdad de ingresos, de acurdo con el más reciente informe de dicha organización internacional OECD (2014).

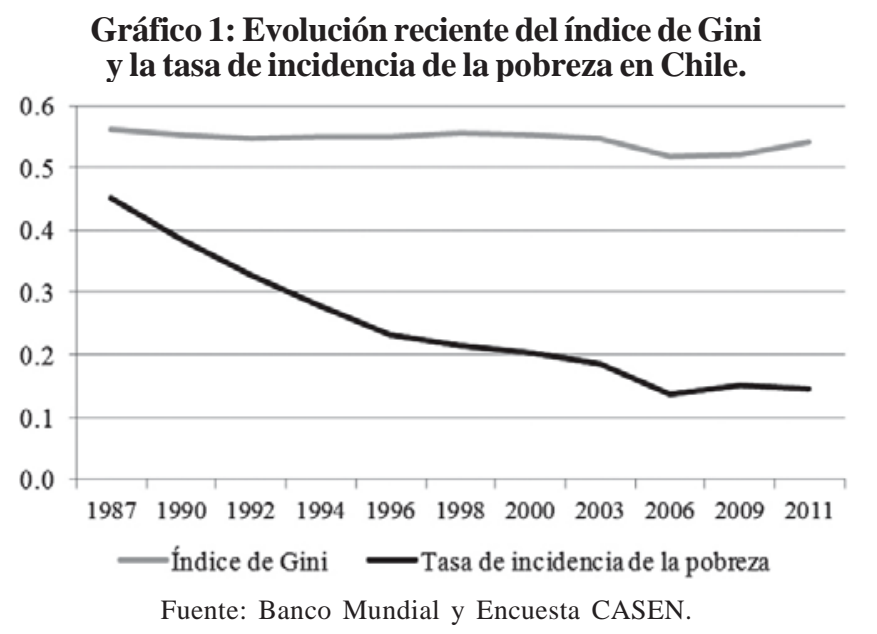

Mientras tanto, en el gráfico 2 se muestra que los frutos del crecimiento económico se han distribuido en forma muy desigual en los extremos de la distribución. Mientras el decil más rico ha experimentado un fuerte crecimiento en sus ingresos durante los últimos años, el decil más pobre no ha conseguido alcanzar mejoras significativas en este indicador de bienestar. 


\section{Gráfico 2: Evolución reciente del ingreso per cápita real de los hogares para los deciles 1 y 10.}

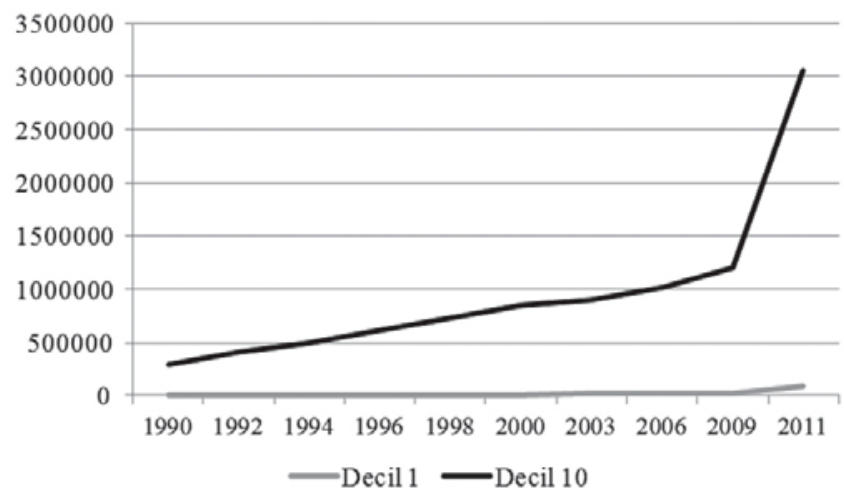

Fuente: Encuesta CASEN.

\section{Las críticas recientes al modelo}

A pesar de sus logros económicos el modelo chileno ha sido objeto de muchas críticas. Una de ellas hace relación a la distribución de la riqueza. Si bien se ha producido una disminución de la pobreza, paralelamente ha aumentado fuertemente la extrema riqueza y su concentración. En efecto, en un estudio reciente de tres economistas, de la Universidad de Chile, se señala que en el país, el ingreso del 1\% más rico percibe el 30\% del total de los ingresos personales totales. Esta estimación la hacen en base a datos del SII para el período 2004-2010 (López et al., 2013).

Los referidos autores señalan lo siguiente: "El tema de la distribución aparece más apremiantemente en los países en desarrollo, y particularmente en Chile y otros de Latinoamérica que han visto crecer sus economías con una enorme desigualdad en la distribución de la riqueza y los ingresos. La preocupación proviene del hecho que las posibilidades de estos países de crecer en el largo plazo se ven amagadas por las negativas consecuencias de la inequidad sobre la inversión en capital humano, la estructura productiva y la productividad de estas economías, así como las amenazas que ella supone para la estabilidad social y política futura”.

En la publicación denominada 95 propuestas para un Chile Mejor (Grupo Res Pública, 2013: cuadro 1, capítulo 13) se muestra un interesante resultado del estudio de la International Social Survey Program aplicado en Chile por el Centro de Estudios Públicos (CEP) en los años 2000 y 2009: las personas de mayores ingresos han tomado más conciencia de que la desigualdad en el país es un problema importante. Dicho estudio muestra que existe un gran consenso respecto a que las diferencias de ingreso en 
Chile son demasiado grandes. Alrededor del $90 \%$ de todos los estratos sociales están de acuerdo con este punto de vista. No existen diferencias significativas en esta respuesta entre las mediciones de los años 2000 y 2009. Sin embargo, cuando se les pregunta si las grandes diferencias de ingreso son necesarias para el desarrollo del país, un 24,4\% del estrato ABC1 dijo estar de acuerdo o muy de acuerdo con ello en el año 2000, mientras que en el año 2009 tal cifra ascendió al 49,1\%. En los estratos más bajos (E) estos porcentajes fueron del 45,2\% en el año 2000 y 41,9\% en el 2009, lo que refleja que las personas más pobres no son tan críticas respecto de la desigualdad de ingresos. Otro punto que resulta interesante constatar en ambas mediciones, es que cuando se pregunta si "es responsabilidad del gobierno reducir las diferencias de ingresos entre las personas con altos ingresos de aquellos con bajos ingresos”, en el año 2000 el 36,7\% de los pertenecientes al estrato ABC1 manifestó estar de acuerdo con ellos, mientras que en los otros estratos C2, C3, D y E las opiniones favorables a este punto fluctuaron entre 62 y 77\%. En el año 2009 en cambio, el estrato ABC1 sube al 58,3\% y los otros se mantienen en torno al 70\%.

Llama la atención que el estrato socioeconómico ABC1 quiere ahora más intervención del Estado (Grupo Res Publica Chile, 2013: 240). Estos resultados rebaten el mito de que la preocupación por la desigualdad en Chile atañe exclusivamente a los pobres. Por el contrario, señalan que los grupos privilegiados sienten gran preocupación por la falta de equidad en la distribución de los beneficios del crecimiento económico.

Otro hecho relevante a tener en cuenta en la actualidad es que la tecnología está jugando un rol preponderante en las comunicaciones sociales, en especial de la gente joven. La masificación de los teléfonos celulares y las redes sociales han permitido que las informaciones fluyan con una rapidez impresionante. Esto ha permitido una mayor interacción de la ciudadanía, que rápidamente es capaz de informarse y reaccionar ante situaciones de interés público. Las coordinaciones para actos públicos se han facilitado, lo mismo que el acceso a noticias que impactan a la ciudadanía, como escándalos o abusos de autoridades o de personeros de cualquier tipo. Ha surgido así una sociedad más empoderada y consciente de sus derechos. Aunque falta quizás avanzar más en empoderar a esta misma sociedad en los deberes que demanda un sistema democrático.

Esta sociedad más empoderada está consciente de las enormes desigualdades que aún persisten en el país. La calidad de la educación en todos sus niveles es algo que ha salido a la luz pública en múltiples ocasiones. Las diferencias abismales entre los colegios municipales, subvencionados y particulares se han hecho evidentes en todas las mediciones. El acceso a la educación básica y media de calidad está determinado, salvo algunas honrosas excepciones, por la capacidad de pago de los padres. La educación básica, media y también la universitaria se ha segregado de acuerdo a la capacidad de pago de las familias.

En relación a la educación superior, desde comienzos de la década de 
los 80 se produce una verdadera explosión de creación de universidades en Chile lo que ha permitido ampliar el acceso a estas instituciones. Hasta comienzos de la década solo existían en Chile 8 universidades, las así llamadas “tradicionales”. La reforma del gobierno militar a comienzos de los 80 crea las llamadas universidades derivadas, nacidas en las sedes regionales de las instituciones tradicionales, utilizando sus campus e instalaciones. Primero se forman las dependientes de las sedes regionales de las Universidades de Chile y Técnica del Estado, luego la Pontifica Universidad Católica de Chile separa sus Sedes de Concepción, del Maule y Temuco. Así, las Universidades que componen el Consejo de Rectores (CRUCH) pasan de 8 a 25. Todas ellas reciben aportes fiscales directos del Estado, además de otros aportes estatales a los cuáles también pueden acceder las instituciones privadas. Estas últimas nacen en los años 80, creadas con pocas exigencias gubernamentales. Hoy varias de ellas se han fusionado o han desaparecido. Los requisitos para abrir universidades se han complejizado, por lo que la creación de nuevas instituciones ha disminuido fuertemente.

Esta mayor oferta universitaria ha creado también una población con mayores niveles de educación, aunque con estándares de calidad disímiles. La mayor cobertura de la educación posiblemente ha contribuido también a un mayor empoderamiento de la ciudadanía, sobre todo de los jóvenes. El tema de la gratuidad de la educación ha aparecido con fuerza. Opiniones contrapuestas se han abierto en este sentido. Mientras unos piensan que la universidad debe ser gratuita para todos, otros señalan que la educación debe ser gratuita para los más pobres y pagada para los más ricos, mientras que los niveles intermedios deberían tener créditos fiscales a pagar una vez terminados los estudios.

Por otro lado, en el acceso a una salud de calidad, se experimenta un fenómeno similar a lo que ocurre con la educación. Existe una marcada segregación de acuerdo a la capacidad de pago de la población. Salud buena para el que puede pagar y regular o deficiente para el que no. La privatización de la salud y la creación del sistema de ISAPRES, si bien han permitido mejorar enormemente la calidad de los servicios prestados, han brindado mejoras que están sólo al alcance de los que tienen ingresos suficientes para acceder a ellas. Lo cual también ha sido fuente de descontento en amplios sectores de la población.

Según un estudio de la encuesta longitudinal de la primera infancia, en Chile (Bravo, 2012) todos nacen con características de peso y talla que son independientes del ingreso familiar. Sin embargo, un test llamado Tepsi, que mide motricidad, coordinación y lenguaje, muestra diferencias significativas tempranas en cuánto al desarrollo infantil, según el nivel de ingreso. Allí sin duda hay una fuente clara de desigualdad. Si bien nacemos iguales, pronto esa igualdad desaparece. Y luego esta desigualdad se manifiesta también en el colegio al que se asiste, en el barrio en el que se vive, en la pertenencia étnica y hasta en el sexo y la edad. En este último caso toma relevancia lo que ocurre con los adultos mayores, población que aumenta significativamente en el país. Esta es una realidad que no es posible cuan- 
tificar con precisión mientras no se disponga de cifras exactas de un censo de población. Pero claramente sabemos que en Chile la población está envejeciendo y que como país no se debe dejar a los adultos mayores en el abandono. Es necesario integrarlos a la sociedad adecuadamente.

Otro aspecto que ha salido a la discusión pública es lo que ocurre con el sistema de pensiones. El envejecimiento de la población y la mayor esperanza de vida, unido a la irregularidad en las cotizaciones han provocado que muchas personas obtengan jubilaciones muy bajas, lo que también ha generado descontento en la población.

\section{El déficit de justicia e igualdad de oportunidades}

El modelo económico chileno ha brindado amplias garantías para el buen funcionamiento del mercado. El ordenamiento macroeconómico que surge a partir del modelo, ha permitido al país disminuir la incertidumbre y atenuar los movimientos cíclicos de la economía. Así como alcanzar notables avances en materia de crecimiento económico.

Sin embargo, se trata de un modelo sustentado en una concepción política que delega al individuo casi la totalidad de la responsabilidad social, relegando al Estado a un rol de garante del buen funcionamiento de la macroeconomía y de proveedor de ciertas garantías mínimas para las personas. Tales garantías, por la misma concepción política en que están fundadas, son insuficientes para que las personas puedan competir en el mercado en condiciones de igualdad de oportunidades.

Si bien, en el modelo, el Estado garantiza unos niveles mínimos de educación, de salud y de seguridad social, tales garantías se mantienen dentro de una profunda desigualdad. El sistema no brinda las condiciones para que las personas adquieran un desarrollo físico e intelectual que les permita explotar sus talentos innatos en condiciones equitativas.

En el proceso de formación de las personas se provee una educación básica y media segregada en tres sistemas disímiles, con grandes diferencias de calidad y de resultados. Tales diferencias se reflejan claramente al momento en que los jóvenes rinden sus pruebas de ingreso a la universidad. Los que proceden de colegios municipales compiten en situación de gran desventaja, mientras que los provenientes de colegios privados exclusivos, compiten en condiciones sumamente privilegiadas. Esta situación no satisface claramente los principios de justicia y de igualdad de oportunidades, por ello ha sido motivo de un fuerte descontento popular y de protestas juveniles en años recientes.

El sistema de salud es también segregado. La atención de salud para las mujeres embarazadas y para los niños, es muy diferente según el origen social de las personas. Aquellas familias de bajos ingresos hacen largas 
filas para que sus hijos y mujeres embarazadas sean atendidos en puestos de salud y hospitales públicos, cuya calidad de servicios es abismalmente inferior a lo que ofrecen las clínicas privadas. El sistema público de salud además colapsa frecuentemente, por su incapacidad para atender la demanda de servicios de las personas de bajos ingresos. ${ }^{4}$ De manera que la vida de las personas muchas veces se ve expuesta, por la falta de recursos para pagar una atención hospitalaria. Esta situación es posiblemente la mayor injusticia que existe en el modelo, puesto que el valor básico más reconocido y compartido de la sociedad contemporánea: la vida humana, no está garantizada como un derecho universal en la atención de salud pública chilena.

El modelo se funda en una concepción política en donde la responsabilidad social se ha transferido casi totalmente al sistema de mercado. Según tal concepción política, cada cual debe hacerse cargo de comprar educación, salud y seguridad para la vejez, de la misma manera que se compra cualquier otro bien en el mercado. Es decir, se trata exactamente de la concepción fundamentalista de mercado, que ya describimos al inicio. Desde tal perspectiva, no tiene sentido una preocupación pública por la justicia social, porque como lo señala Hayek (1976, 1978), la justicia social es un concepto carente de contenido real. Mientras que el libre juego del mercado, desde esta perspectiva, no exige como prerrequisito una igualación del campo de juego. Los “activos de cuna” se consideran justos para participar en la competencia, porque son el fruto del esfuerzo y de las ventajas que obtuvieron en el juego las generaciones anteriores.

El problema de esta concepción es que los ciudadanos no están situados de manera simétrica en el juego. El modelo no promueve, ni representa una sociedad que se construye a partir de un contrato social y de un acuerdo entre personas constitutivamente iguales. Se trata más bien, de una sociedad donde los ciudadanos se clasifican en distintas categorías, según sus “activos de cuna”. En el sistema de educación básica y media, se forjan ciudadanos de tres categorías: los que provienen de colegios municipales, los que provienen de colegios subvencionados y los que provienen de colegios particulares. En el sistema de salud, existen tres tipos de ciudadanos: los que acceden al sistema público, los que acceden al sistema privado y los que ni siquiera pueden acceder a algún tipo de seguro de salud. Al final de sus vidas, las personas envejecen clasificadas también en varios tipos de ciudadanos, de acuerdo al monto que puedan haber ahorrado durante su vida laboral, independientemente de las desventajas que hayan tenido para competir durante su período productivo.

Los defensores del modelo se muestran luego sorprendidos ante las pujantes demandas de la sociedad civil empoderada y tratan de ingeniar algunas explicaciones exotéricas al descontento social. Paradójicamente, las demandas mismas son atribuidas frecuentemente al éxito del modelo. Se explican como resultado de una clase media emergente que ha surgido justamente debido a la prosperidad económica de Chile. Pero en realidad, las protestas que levantan los movimientos sociales solo son el reflejo de la 
inconformidad con una democracia desigual, en donde hay ciudadanos de tercera categoría y en donde la desigualdad de oportunidades es evidente.

Las protestas estudiantiles que se intensificaron en el año 2011 son las que han manifestado con mayor claridad la fuente de tal descontento social. Cuando los estudiantes criticaron el lucro en la educación no estaban indicando que la educación privada debería desaparecer. Lo que enfatizaron es que la educación no debe ser vista como una mercancía más, sino como un derecho, al que todas las personas deben tener la oportunidad de acceder, en igualdad de condiciones. Cuando los estudiantes demandaban una educación de calidad para todos, lo que estaban tratando de expresar es que todos deben tener las mismas oportunidades para formarse y para desarrollar sus talentos innatos, independientemente de su origen social.

Lo que observamos entonces es un modelo exitoso en términos macroeconómicos, pero con un profundo déficit en términos de justicia e igualdad de oportunidades. El juego del mercado, no se está jugando en una cancha pareja.

\section{Conclusiones y recomendaciones}

El modelo económico chileno, que fue fundado bajo el régimen militar de Augusto Pinochet, obedece a una lógica de fundamentalismo de mercado que tiene su origen en los desarrollos intelectuales de Ludwig von Mises, Friedrich von Hayek y Milton Friedman. Este modelo que se implementó en el contexto de la Guerra Fría y que continuó desarrollándose durante el período democrático de las últimas décadas, ha demostrado en la práctica ser muy exitoso en términos macroeconómicos y en la generación de condiciones adecuadas para el desarrollo de los negocios. Debido a ello, Chile se muestra como ejemplo para América Latina en materia de crecimiento económico, control de la inflación y estabilidad fiscal. Ha obtenido además importantes logros sociales, tales como la reducción de la pobreza, el aumento de la esperanza de vida al nacer, el incremento del ingreso per cápita, el aumento de la cobertura de la educación terciaria y la expansión de la clase media.

Sin embargo, Chile sigue siendo hoy un país muy desigual. El modelo no ha sido capaz de generar mejoras sustanciales para equiparar la cancha de las oportunidades que tienen los ciudadanos para competir por alcanzar una determinada posición en la sociedad. Por esa razón, importantes sectores de la población han manifestado su descontento frente al modelo. Algunos grupos extremistas abogan incluso por su destrucción.

Desde nuestra perspectiva no obstante, sin dejar de reconocer las bondades del modelo, se deben indicar los aspectos en los que éste debería reformarse para que la sociedad chilena avance hacia una mayor inclusión en términos de justicia y de igualdad de oportunidades en el sentido de 
Rawls (1971, 1993, 2001) y de Roemer (1998).

Para ello, el modelo requiere abandonar algunos dogmas propios del fundamentalismo de mercado y reconocer que el mecanismo de mercado es solo un medio al servicio de la sociedad política y no un fin en sí mismo. Es la economía la que debe estar al servicio de la sociedad política y no al revés.

Los desafíos que hoy se plantea la sociedad chilena, apuntan a la búsqueda de un consenso entrecruzado como el que nos señala Rawls (2001), alrededor de las reformas necesarias para avanzar en la construcción de una estructura básica que brinde mayor igualdad de oportunidades para los ciudadanos. Ello debe ser fruto de un acuerdo entre individuos libres e iguales en dignidad y en derechos.

A nuestro juicio hay mucho que hacer para poder avanzar en tal dirección. Pero hay dos aspectos que son prioritarios y que deberían estar en la primera línea de la agenda política. El primero de ellos es realizar una reforma educacional que permita igualar la cancha en la formación preescolar, básica y media. Para que todos los niños y niñas de Chile reciban una educación de calidad, que les permita desarrollar sus talentos en forma adecuada. De modo que puedan competir después en el mercado, en condiciones de mayor igualdad. Paradójicamente, las prioridades parlamentarias hoy en día se han enfocado en la educación universitaria, en donde las desigualdades ya están dadas. De manera que las prioridades no se han puesto en donde se generan las desigualdades, sino en donde los grupos de interés tienen mayor poder de incidir en las decisiones políticas.

Otro de los aspectos que consideramos prioritarios es el de avanzar hacia un sistema de salud que sea capaz de proveer igual calidad de asistencia a todos los ciudadanos, independiente de sus niveles de ingresos. Los seres humanos somos todos distintos en esfuerzo y en talento, pero somos iguales en dignidad. La vida humana no vale más para unos, que para otros. Así que para avanzar hacia una sociedad éticamente más justa y equitativa, es fundamental igualar la cancha en la atención a la salud y la preservación de la vida y de las capacidades de todas las chilenas y chilenos.

Para finalizar, conviene enfatizar que una sociedad bien ordenada como la que describe Rawls (2001) es en sí una idealización, que no se alcanza nunca, pero que nos señala claramente el camino hacia donde debemos transitar poco a poco para obtener un desarrollo más justo y equitativo. 


\section{Notas}

1 Las razones por las que en la posición original escogeríamos estos principios son las siguientes: nadie estaría dispuesto a renunciar a su libertad (igual libertad); todos quisiéramos mantener al menos una situación de iguales y poder además contar con la oportunidad de explotar al máximo nuestros talentos (igualdad de oportunidades); si nos tocase la peor situación nos gustaría que la sociedad no nos dejase en el abandono, por lo tanto quisiéramos maximizar el bienestar de quien estaría peor (principio de diferencia).

${ }^{2}$ Este principio ha sido llamado también principio de maximin, sin embargo Rawls (2001), considera que tal término es inapropiado.

${ }^{3}$ En este punto Roemer (1998) va incluso más allá, pues considera necesario brindar una compensación en la forma de un mayor apoyo en la formación de aquellos con menores capacidades innatas.

${ }^{4}$ Durante los períodos invernales por ejemplo, en Chile colapsan los hospitales públicos en la atención pediátrica a las enfermedades respiratorias. 


\section{Bibliografía}

Atria, F., Larraín, G., Benavente, J., Couso, J., Joignant, A. (2013), El otro modelo: del orden neoliberal al régimen de lo público. Editorial Random House Mandatori, Santiago, Chile.

Bravo, D. (2012), Encuesta Longitudinal de la Primera Infancia. Centro Micro Datos Departamento Economía Universidad de Chile

Coeymans, J. (1999), “Ciclos y crecimiento sostenible a mediano plazo en la economía chilena”. Cuadernos de Economía, 36(107): 545-596.

De Castro, S. (1973), El ladrillo. Centro de Estudios Públicos CEP. Santiago

Grupo Res Publica Chile (2013), 95 Propuestas para un Chile mejor. Santiago.

Hayek, F. (1944), The road of serfdom, University of Chicago Press. Traducido al español como: Camino de Servidumbre, Alianza Editorial, 2007, Madrid.

Hayek, F. (1976), Law, Legislation and Liberty, Volume 2: The Mirage of Social Justice, University of Chicago Press, Chicago.

Hayek, F. (1978), New studies in philosophy, politics, economics and the history of ideas. University of Chicago Press, Chicago.

Hayek, F. (1988), The Fatal Conceit: The Errors of Socialism, University of Chicago Press, Chicago. Traducido al español como: La Fatal Arrogancia: Los errores del socialismo, Unión Editorial, 1990, Madrid.

Larrain, F., Vergara, F. (2001), La transformación económica de Chile. Centro de estudios públicos. CEP.

Luders, R. (2012), La Misión Klein-Saks, los chicago-boys y la Política Económica. Documento de trabajo. Instituto de Economía. Pontificia Universidad Católica de Chile.

López, R., Figueroa, E., Gutiérrez, P. (2013), La “parte del león”: Nuevas estimaciones de la participación de los súper ricos en el ingreso de Chile. Serie documentos de trabajo. Departamento de Economía. Universidad de Chile.

OECD (2014), Society at a Glance 2014: OECD Social Indicators, OECD Publishing. http://dx.doi.org/10.1787/soc_glance-2014-en.

Rawls, J. (1971), A theory of justice, Harvard University Press. Traducido al español como: Teoría de la Justicia, Fondo de Cultura Económica, 1979, México. 
Rawls, J. (1993), Political liberalism, Harvard University Press. Traducido al español como: El liberalismo político, Biblioteca de Bolsillo, 2004, Barcelona.

Rawls, J. (2001), Justice and fairness. Harvard University Press. Traducido al español como: La Justicia como Equidad: Una reformulación, Editorial Paidos, 2004, Buenos Aires.

Rivera, E., Martner, G. (2013), Radiografía crítica al “modelo chileno”. LOM Ediciones, Santiago.

Roemer, J. (1998), Equality of Opportunity, Harvard University Press.

Recibido: 15.10.2013

Aceptado: 30.07.2014 